\title{
How Prepared Are Hospitals' Emergency Management Capacity? Factors Influencing Efficiency of Disaster Rescue-ERRATUM
}

Lijun Gao; Qunhong Wu; Ye Li; Ding Ding; Yanhua Hao; Yu Cui; Zheng Kang; Mingli Jiao; Libo Liang; Adamm Ferrier; Ning Ning; Hong Sun

doi:10.1017/dmp.2016.25, Published by Cambridge University Press, 18 May 2016.

I $\mathrm{n}$ the Original Article titled "How Prepared Are Hospitals' Emergency Management Capacity? Factors Influencing Efficiency of Disaster Rescue" (originally published online May 18, 2016) the respective contributions of specific authors as indicated originally were published with errors. The correct attribution details are as follows:

Lijun Gao, MPH; $;^{\dagger}$ Qunhong Wu, MD; Ye Li, MD; ${ }^{\dagger}$ Ding Ding, MPH; ${ }^{\dagger}$ Yanhua Hao, MD; Yu Cui, MD; Zheng Kang, PhD; Mingli Jiao, MD; Libo Liang, MD; Adamm Ferrier, MD; Ning Ning, MD; Hong Sun, MD

$\dagger$ Authors contributed equally to the first author.

\section{REFERENCE}

Gao L, Wu Q, Li Y, Ding D, Hao Y, Cui Y, Kang Z, Jiao M, Liang L, Ferrier A, Ning N, Sun H. How Prepared Are Hospitals' Emergency Management Capacity? Factors Influencing Efficiency of Disaster Rescue. Disaster Medicine and Public Health Preparedness. 2016. doi: 10.1017/dmp.2016.25.

Published online: August 18, 2016. 